\title{
Палеоклиматические и природно-динамические изменения окружающей среды в голоцене на юге Мурманской области: результаты изучения донных осадков озер в районе Лувеньгских тундр
}

\author{
Николаева С.Б. ${ }^{1}$, Лаврова Н.Б. ${ }^{2}$ \\ ${ }^{1}$ Геологический институт КНЦ РАН, Anamumbl,nikolaeva@geoksc.apatity.ru \\ ${ }^{2}$ Институт геологии КарНЦ РАН, lavrova@krc.karlia.ru
}

\begin{abstract}
Аннотация. Приводятся новые данные палинологического и литолого-стратиграфического изучения донных отложений их двух озерных котловин, расположенных в районе низкогорных массивов Лувеньгских тундр (Кольский полуостров). Изучение осадочных разрезов позволило выделить особенности озерной седиментации, формировавшейся в условиях позднеледниковых и голоценовых тектонических перемещений земной коры, установить основные этапы формирования озер, реконструировать динамику растительности в голоцене.

Ключевые слова: донные осадки, литология, климат, голоцен, Лувеньгские тундры, Мурманская область.
\end{abstract}

\section{Reconstruction of paleoenvironmental changes in the south of Murmansk region during the Holocene: results of study the lake sediments in the Luvenga mountains area}

\author{
Nikolaeva S.B. ${ }^{1}$, Lavrova N.B. ${ }^{2}$ \\ ${ }^{1}$ Geological Institute of Kola Science Center RAS, Apatity,nikolaeva@geoksc.apatity.ru \\ ${ }^{2}$ Institute of Geology of Karelian Research Centre RAS, lavrova@krc.karelia.ru
}

\begin{abstract}
New data of lithostratigraphic and pollen analysis of bottom sediments from two lake basins located in the Luvenga mountains area (Kola region) are presented. Based on the study of bottom sediments, the features of sedimentation in lakes, which were formed under the conditions of late glacial and Holocene tectonic movements, were identified. We have established the main stages of lake formation and reconstruction of the Holocene vegetation dynamics.

Key words: lake bottom sediment, lithology, climatic conditions, Holocene, Luvenga mountains, Murmansk region.
\end{abstract}

\section{Введение}

В арктических и субарктических областях уже на протяжении многих лет проводятся палеогеографические исследования, направленные на реконструкцию природных обстановок окружающей среды. Одно из направлений, входящих в такие исследования - изучение стратиграфии донных осадков озер, в которых сохраняется информация о прошлых седиментационных и природноклиматических обстановках. При пополняющемся объеме информации о палеогеографии Кольского региона многие вопросы остаются за пределами внимания исследователей. В их числе и соотношение эволюционных и катастрофических процессов в изменении природных обстановок.

В представленном сообщении приводятся новые данные литолого-стратиграфического и палинологического изучения донных отложений (ДО) озер района низкогорных массивов Лувеньгских тундр, сложенных в основном палеопротерозойскими гранулитами и глиноземистыми гнейсами Лапландского гранулитового пояса. Цель исследований состояла в выявлении особенностей озерной седиментации в условиях новейших тектонических перемещений земной коры в пределах активной блоковой Колвицкой морфоструктуры Кольского региона, и в сочетании с опубликованными ранее палеогеографическими реконструкциями, выделении основных климатических этапов осадконакопления конкретного микрорайона.

\section{Результаты исследований}

Характеристика озерных котловин и литология осадков. В районе исследования изучены ДО двух озерных котловин - Уросиха и Рига-Ламбина, расположенных на высотной отметке 136.0 м 


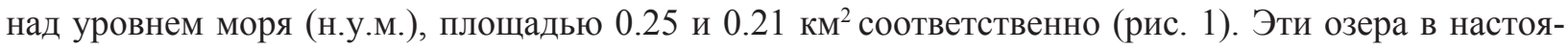
щее время соединяются заболоченной протокой с приразломной котловиной озера Среднее Лувеньгское (водосбор р. Нива). Скальные уступы, ограничивающие приразломную котловину, осложнены сейсмодислокациями, смещающими поверхность ледниковой экзарации на первые десятки метров (Колодяжный и др., 2019). Территория водосборной площади по типу ландшафтов относится к таежной зоне с высотами от 500 до 785 м.

Литология осадков, изученная по скважинам РЛ-1 и УР-2, имеет сходное двучленное строение (рис. 1). При бурении с глубин 4.5 м и 6.5 м от поверхности воды подняты керны, представленные снизу вверх: (I) толщей переслаивающихся тонкозернистых песков с алевритом и прослойками глин с включением зерен гравия (20-70 см), и гиттией (278-308 см) (толща II). Базальная часть толщи II сложена алевритистой бурой гиттией (6-8 cм), переходящей в темно-бурую опесчаненную (30-40 см), сменяющуюся сапропелями коричневых оттенков (2.0-2.7 м). В интервале 752-744 см разреза РЛ-1 отобрана проба, показавшая возраст 10460 180 (ЛУ-7573) календарных лет (рис. 2).

Особенностями литологии изученных разрезов являются деформации, часто встречаемые в донных осадках озер, сопряженных с сейсморвами: наклонное залегание слоев, складки и различные признаки возмущения гидродинамической обстановки (Лукашов, 2004). Так в разрезе УР-2, в интервале глубин 965-970 см хорошо виден наклонный слоек глины ( $\left\llcorner 10-12^{\circ}\right)$, мощностью 1.3 см и изгибы слоев, а выше по разрезу, в интервале глубин 920-910 см, в опесчаненной гиттии обнаруживаются фестончатые узоры, изгибы слоев и признаки ликвефакции (рис. 1). В разрезе РЛ-1 обращают на себя внимание прослои детритового сапропеля (detritus gyttja) в толще обычной слоистой гиттии и обилие крупных веточек, длиной до 2-3 см в интервале 750-730 см.

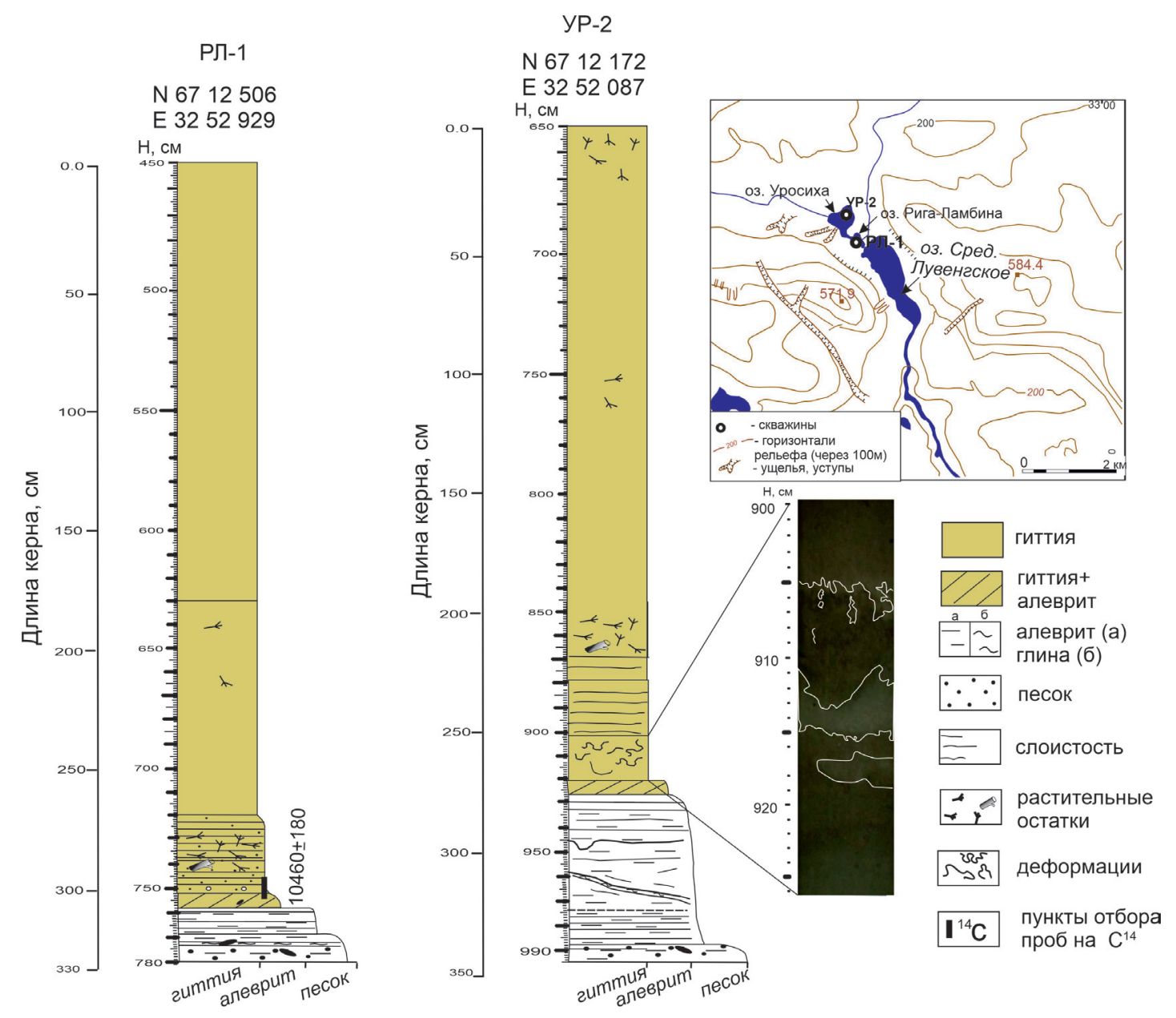

Рис. 1. Литостратиграфия донных осадков и расположение изученных озер.

Fig. 1. Lithostratigraphy of bottom sediments and locations of studied lakes. 
Палинологический анализ проведен по разрезу РЛ-1 (рис. 2). В озерных осадках выделено 4 локальных пыльцевых зоны (ПЗ) и две подзоны (табл.).

Таблица. Спорово-пыльцевые зоны разреза донных отложений озера Рига-Ламбина.

Table. Spore-pollen zones of Riga-Lambina bottom sediments.

\begin{tabular}{|c|c|c|}
\hline $\begin{array}{c}\text { № } \\
\text { зоны }\end{array}$ & $\begin{array}{c}\text { Глубина, } \\
\text { см }\end{array}$ & Описание \\
\hline I & $770-752$ & $\begin{array}{l}\text { В ПЗ, выделенной в слоистых алевритах с гиттией, зафиксировано самое низкое за } \\
\text { все время накопления осадков количество пыльцы древесных пород (45-60 \%), сре- } \\
\text { ди которых преобладает пыльца Betula sect. Albae. Отмечена пыльца Betua nana (3-5\%), } \\
\text { незначительное количество Salix. Среди кустарничков и трав доминирует пыльца } \\
\text { Ericales и Сурегасеае. В группе споровых первую позицию занимает Bryales. Соглас- } \\
\text { но полученным данным и датировке из выше залегающих отложений (рис. 2) палино- } \\
\text { зона отнесена к заключительному этапу пребореального периода (РВ). }\end{array}$ \\
\hline II & $752-733$ & $\begin{array}{l}\text { Отличительная особенность ПЗ ІІ, в которой начинает накапливаться опесчаненная } \\
\text { гиттия - это увеличение количества пыльцы древесных пород, главным образом, за } \\
\text { счет пыльцы Pinus (от } 8 \text { до 55 \%). С этого времени пыльца Pinus доминирует в донных } \\
\text { отложениях, так же как и в отложениях оз. Имандра (Lenz et al., 2020). Вклад пыльцы } \\
\text { Betula sect. Albae составляет 30-37 \%. Эти изменения в CПC, а также корреляция с ра- } \\
\text { нее опубликованными диаграммами (Елина и др., 2000; Kremenetski et al., 1997), по- } \\
\text { зволяет предположить, что СПС ПЗ были сформированы в бореальный период (ВО). } \\
\text { Это подтверждается датировкой } 9240 \pm 150^{14} \mathrm{C} \text { (ЛУ-7573), полученной из отложений, } \\
\text { соответствующих нижней границе палинозоны. }\end{array}$ \\
\hline III a & $733-665$ & $\begin{array}{l}\text { ПЗ соответствует буровато-коричневой и бурой гиттии. Здесь господствует пыльца } \\
\text { древесных, среди которой первое место принадлежит Pinus ( 60 \%). Идентифици- } \\
\text { рованы единичные пыльцевые зерна термофильных древесных пород (Ulmus, Tilia). } \\
\text { По данным Kremenetski et al. (1997) широкое распространение сосны на Кольском } \\
\text { п-ве происходило между 8000-7000 л.н. Учитывая вышесказанное, можно утверж- } \\
\text { дать, что СПС рассматриваемой ПЗ были сформированы в начале атлантического пе- } \\
\text { риода (АТ1). }\end{array}$ \\
\hline Ш b & $665-556$ & $\begin{array}{l}\text { Изменения в СПС этой зоны следующие: увеличение вклада и разнообразия таксо- } \\
\text { нов пыльцы термофильных пород (Ulmus, Quercus, Tilia, Corylus), некоторое сниже- } \\
\text { ние доли пыльцы Pinus ( } 45-50 \% \text { ). Данные анализа и корреляция их с опубликован- } \\
\text { ными материалами (Kremenetski et al., 1997; Solovieva, Jones, 2002) позволяют пред- } \\
\text { положить, что СПС субпалинозон Ш а и Ш b были сформированы в атлантическое } \\
\text { время (АТ). }\end{array}$ \\
\hline IV a & $556-528$ & $\begin{array}{l}\text { Нижней границе субпалинозоны IVa соответствует эмпирическая граница пыльцы } \\
\text { Picea. Для спектров субпалинозоны характерно исчезновение пыльцы термофильных } \\
\text { древесных пород. Отмечено увеличение вклада Pinus, снижение Betula sect. Albae и } \\
\text { Alnus. Возрастает доля пыльцы Betula nana, Juniperus, Ericales. В СПС данной зоны } \\
\text { нашло отражение похолодание, имевшие место в начале суббореального периода } \\
\left(\mathrm{SB}_{1}\right) \text {. }\end{array}$ \\
\hline $\mathrm{IVb}$ & $528-477$ & $\begin{array}{l}\text { СПС отличаются появлением единичных пыльцевых зерен термофильных пород } \\
\text { (Ulmus, Tilia, Corylus). Участие в спектрах пыльцы Pinus составляет } ~ 43 \text { \%, Betula } \\
\text { sect. Albae u Picea - 8-12 \% и 3-6 \% соответственно. Возрастает доля пыльцы Cурега- } \\
\text { сеае и Роасеае. Возможно, изменения в спектрах обусловлены потеплением, последо- } \\
\text { вавшим после похолодания в раннем суббореале. Это позволяет предположить, что } \\
\text { формирование палиноспектров происходило в суббореале (SB). }\end{array}$ \\
\hline
\end{tabular}

\section{Обсуждение результатов и выводы}

Литостратиграфический анализ позволил выделить в ДО озер две фациальные разновидности: кластогенную и органогенную, соответствующих фациям I (приледникового озера) и V (современного пресноводного озера) (Колька и др., 2013). Вскрытые в базальных частях разрезов пески и алевриты накапливались в перигляциальных обстановках, в условиях деградирующего на запад ледника. Следует отметить, что опробованные скважины вскрыли толщу кластогенных осадков не на всю мощность, поэтому можно с большой долей уверенности предположить, что ДО озера РигаЛамбина стали формироваться, начиная с конца позднего дриаса - начала пребореала, когда край ледникового фронта находился или вблизи или уже за пределами горных массивов Кандалакшских 


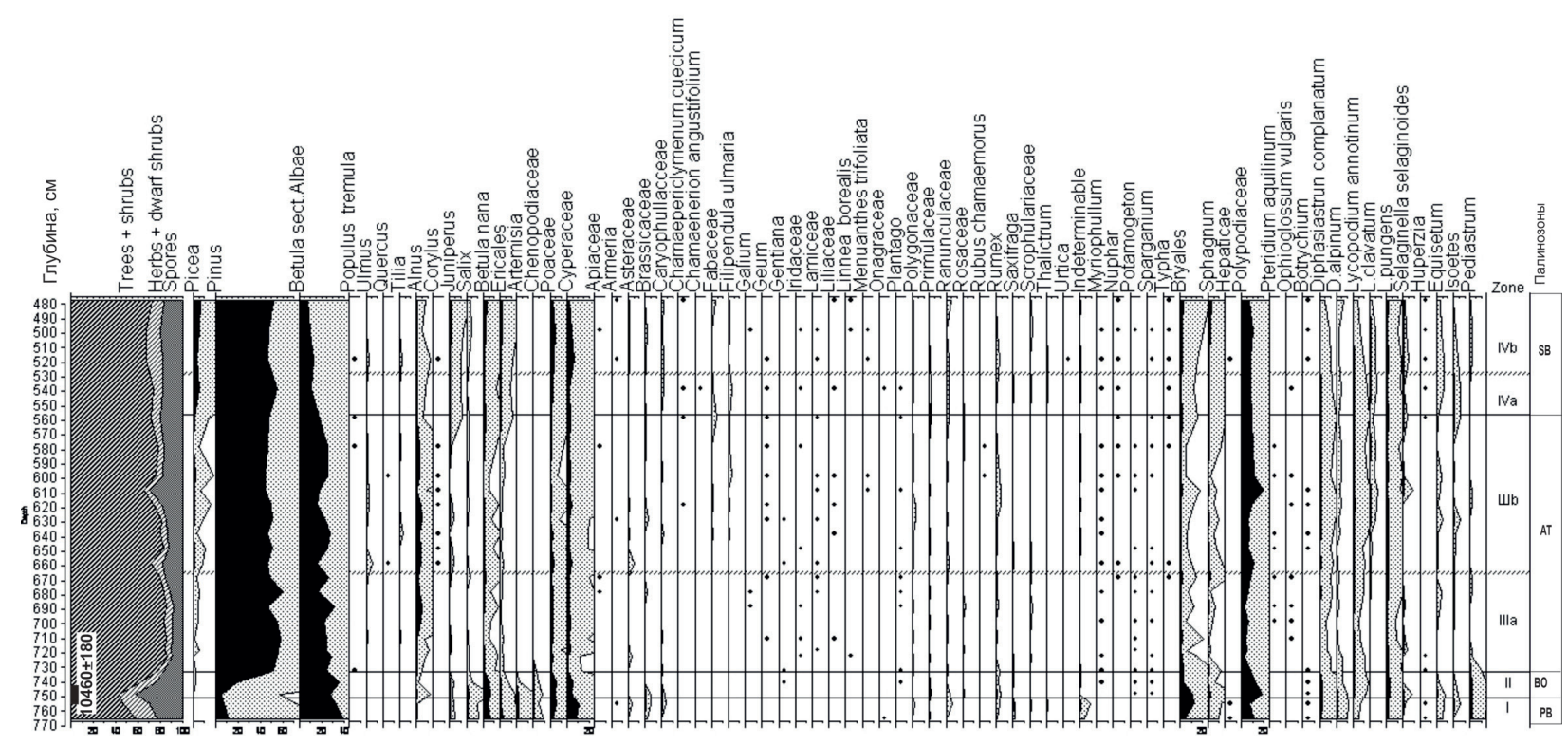

Рис. 2. Спорово-пыльцевая диаграмма разреза донных отложений озера Рига-Ламбина, отражающая изменение климата в районе Лувеньгских тундр.

Fig. 2. Spore-pollen diagram of Riga-Lambina basin, indicated the changes in vegetation during the Holocene in the Luvenga mountains area.

и Лувеньгских тундр. Котловины озер Уросиха, Рига-Ламбина и озера Среднее Лувеньгское в это время представляли собой единый глубокий водоем, сформировавшийся вероятно в ложбине доледникового заложения. Дальнейший седиментогенез осадков происходил уже на протяжении всего голоцена, когда в депрессиях озер стала накапливаться органика.

Реконструкция динамики растительности на изучаемой территории выполнена с пребореала. В первую фазу в пребореальный период, в районе Лувеньгских тундр преобладали березовые редколесья (B. czerepanovii, с участием Betula pubescens) с кустарничковым ярусом и покровом из зеленых мхов наряду с тундровыми сообествами (кустарничково-зеленомошными и ерниковозеленомошными). Подобная растительность реконструирована для других регионов Кольского полуострова (Kremenetski et al., 1997; Сапелко и др., 2015). В водоеме накапливался алеврит, сменившийся формированием опесчаненной темно-бурой гиттии с алевритом - переходной зоны к формированию сапропелей. Это может указывать на повышение прироста планктона и бентоса, а также на то, что процессы эрозии в условиях не полностью сомкнутого растительного покрова были еще весьма значимы. Комплекс водорослей Pediastrum (Pediastrum integrum var. integrum, P. duplex var. rugulosum) свидетельствует о существовании довольно холодного, глубоководного озера (Komarek, Jankovska, 2001). Такие условия лимитировали распространение водной растительности и зарастание водоема.

В бореальный период тундровые кустарничковые сообщества вытесняются березовыми редкостойными лесами. В начале этого периода 10. 5 тыс. л. н. в озере Рига-Ламбина стала накапливаться органика. К концу периода преобладали сосновые леса северотаежного облика. О редкостойности лесов свидетельствует значительное присутствие спор плаунов (Lycopodium annotinum, L. pungens, Diphasiastrum complanatum, D. alpinum), пыльцы Juniperus, довольно низкая насыщенность осадков пыльцой. В депрессиях рельефа с проточным увлажнением, на берегах водоема, вероятно, произрастали крупнотравные березовые леса. Мелководья озера начали зарастать водными и прибрежно-водными видами. В этот период продолжается накопление слоистой опесчаненной гиттии. В осадках появляется большое количество макро- и микроостатков растений, отмечаются прослои «detritus gytta», состоящие только из дисперсной органики. Эти изменения в литологии осадков могли быть связаны с разными причинами. Одна из них это падение уровня воды в озере вследствие ксерофитизации климата. В результате возникли условия для развития бентоса и план- 
ктона, водной и прибрежно-водной растительности, что и способствовало формированию сапропелей. Малая мощность этих осадков, возможно, обусловлена низкой скоростью осадконакопления, когда продуктивность озера была еще невелика, а привнос материала с водосбора озера значительно сократился вследствие сухих климатических условий и в связи с возрастанием сомкнутости растительного покрова, препятствующего эрозии. Другая причина изменения в литологии осадков могла быть связана с одномоментным вбросом растительных остатков с окрестных возвышенностей в результате эрозионного сноса или же с тектоникой (Арманд, Самсонова, 1969; Колодяжный и др., 2019). Вполне вероятно, что с началом накопления органики в озере, то есть 10280-10640 л. н., сопряжено раскрытие Средне-Лувеньского грабена. Это предположение не лишено оснований, поскольку хорошо известно, что в условиях избыточного переувлажнения раскрытие сейсмотектонических рвов всегда сопровождается образованием озер и накоплением в них органики (Лукашов, 2004). Деформации в виде фестончатых рисунков, складок и явлений возмущения озерной гидродинамики в гиттии разреза УР-2 можно интерпретировать как результат осаждения частиц, занесенных во взвеси с мелководья, вызванного сейсмическими волнами, которые затем повторно отложились. Аналогичная интерпретация наблюдаемых явлений приводится и в работах зарубежных исследователей (Ojala et al., 2018).

Атлантический период - время климатического оптимума голоцена (Ilyashuk et al., 2005). На изучаемой территории произрастали березово-сосновые леса с примесью ольхи. Снижение вклада в палиноспектры спор Lycopodiaceae и встречаемости пыльцы Juniperus косвенно свидетельствует об увеличении сомкнутости лесов, которые приобретали среднетаежный облик. Мелководья палеоводоема активно зарастали водными и болотными растениями. По нашим представлениям, появление в спектрах пыльцы термофильных пород связано с ветровым заносом и указывает на то, что северная граница этих пород значительно приблизилась к изучаемой территории, что было обусловлено изменением климата в сторону повышение влаго- и теплообеспеченности. Это совпадает и с реконструкциями климата других авторов (Kremenetski et al., 1997; Елина и др., 2000; Сапелко и др., 2015).

В суббореальный период в растительные сообщества началось внедрение ели. Еловые леса с березой, кустарничково-моховые сообщества, предпочитали увлажненные подножия склонов, понижения рельефа. Тем не менее, на протяжении SB и SA периодов основной лесообразующей породой оставалась сосна, образующая сосновые и елово-сосновые, с примесью березы, леса. Увеличение в СПС количества пыльцы можжевельника указывает на то, что лесные сообщества стали более разреженными, вследствие похолодания 4500 л. н. На ЮВ Кольского полуострова пик похолодания пришелся на интервал времени 4500-4100 л. н. (Kremenetski et al., 1997). Леса сохранили облик северотаежных и в субатлантическом периоде.

Сопоставление палинологических данных по отдельным районам региона показало, что спектры одних и тех же временных интервалов имеют как общие, так и специфические особенности, обусловленные положением озер на разных гипсометрических отметках и влиянием локальных фитоценозов.

\section{Выводы}

1. В разрезах донных осадков озер района Лувеньгских тундр установлены литологические фации, характеризующие историю развития этого района в позднем плейстоцене и голоцене. Строение и литология ДО свидетельствует о смене условий осадконакопления, связанной с изменениями климата, характера растительности, интенсивности эрозионных процессов на водосборе и палеосейсмическими явлениями.

2. На основании результатов СПА выделено 4 локальных пыльцевых зоны, отражающие смены фаз растительности от пребореала до субатлантического периода голоцена. Установлено, что начало осадконакопления в озерах относится ко времени $10460 \pm 180$ календарных лет назад. В это время исследуемая территория уже была освобождена от ледника. 
3. Сопряженность изученных озерных котловин с приразломной межгорной депрессией, обобщение имеющихся палеосейсмологических и палеогеографических данных, позволили установить время раскрытия Средне-Лувеньгского сейсмограбена, приуроченное к границе пребореаланачала бореала.

Работа выполнена в рамках госзаданий по темам НИР ГИ КНЦ РАН № 0226-2019-0054, ИГ Кар НЦ РАН № AААА-А18-118020690231-1

\section{Литература}

1. Арманд А.Д., Самсонова Л.Я. Морские отложения и голоценовая тектоника района Кандалакши // Основные проблемы геоморфологии и стратиграфии антропогена Кольского полуострова. Л. Изд-во: Наука. 1969. С. 96-111.

2. Елина Г.А., Лукашов А.Д., Юрковская Т.К. Позднеледниковье и голоцен Восточной Фенноскандии (палеорастительность и палеогеография). Петрозаводск. 2000. 242 с.

3. Колодяжный С.Ю., Балуев А.С., Зыков Д.С. Структура и эволюция северо-запада БеломорскоСеверодвинской зоны сдвига в позднем протерозое и фанерозое (Восточно-Европейская платформа) // Геотектоника. 2019. № 1. С. 62-86. https://doi.org/10.31857/S0016-853X2019162-86.

4. Колька В.В., Евзеров В.Я., Мёллер Я.Й., Корнер Д.Д. Перемещение уровня моря в позднем плейстоценеголоцене и стратиграфия донных осадков изолированных озер на южном берегу Кольского полуострова, в районе поселка Умба // Известия РАН. Серия географическая. 2013. № 1. С. 73-85. http://dx.doi. org/10.15356/0373-2444-2013-1-73-88.

5. Лукашов А.Д. Геодинамика новейшего времени // Глубинное строение и сейсмичность Карельского региона и его обрамления (ред. Шаров Н.В. ). Петрозаводск. Изд-во: КарНЦ РАН. 2004. С. 150-191.

6. Сапелко Т.В., Колька В.В., Евзеров В.Я. Динамика природной среды и развития озер в позднем плейстоцене и голоцене на южном берегу Кольского полуострова (район пос. Умба) // Труды КарНЦ РАН. Сер. Лимнология. 2015. № 5. С. 60-69. 10.17076/lim55.

7. Ilyashuk E.A., Ilyashuk B.P., Hammarlund D. and Larocque I. Holocene climatic and environmental changes inferred from midge records (Diptera: Chironomidae, Chaoboridae, Ceratopogonidae) at Lake Berkut, southern Kola Peninsula, Russia // The Holocene. 2005. V. 15. P. 897-914.10.1191/0959683605hl865ra.

8. Komarek J., Jankovska V. Rewiew of the green algal genus Pediastrum: implication for pollen analytical research // Bibliotheca phycologica. Band 108. Berlin; Stuttgart; Cramer. 2001. 127 p.

9. Kremenetski C.V., Vaschalova T., Goryachkin S., Cherkinsky A., Sulerzhunski L. Holocene pollen stratigraphy and bog development in the west of the Kola Peninsula, Russia // Boreas. 1997. V. 26. P. 91-102. 10.1111/ j.1502-3885.1997.tb00656.x.

10. Lenz M., Savelieva L., Frolova L., Cherezova A., Moros M., Baumer M. M., Gromig R., Kostromina N., Nigmatullin N., Kolka V., Wagner B., Fedorov G. \& Melles M.: Lateglacial and Holocene environmental history of the central Kola region, northwestern Russia revealed by a sediment succession from Lake Imandra // Boreas. 2020. V. 50 (1). P. 1-25. https://doi.org/10.1111/bor.12465.

11. Ojala, A.E.K., Mattila, J., Hämäläinena J., Sutinen, R. Lake sediment evidence of paleoseismicity: Timing and spatial occurrence of late- and postglacial earthquakes in Finland // Tectonophysics. 2019. V. 771. P. 1-19. 10.1016/j.tecto.2019.228227. 